\title{
Equoterapia: suas repercussões nas relações familiares da criança com atraso de desenvolvimento por prematuridade
}

\author{
Therapeutic riding: repercusion on family relations of \\ children with prematureness development delay
}

\author{
Juliana Fonsêca de Queiroz MARCELINO \\ Zélia Maria de MELO $\mathbf{M}^{2,3}$
}

\begin{abstract}
Resumo
A pesquisa tem como objeto de estudo crianças que apresentam atraso de desenvolvimento global devido à prematuridade e que estão em atendimento interdisciplinar em equoterapia, abordagem terapêutica que tem como recurso o cavalo e seu ambiente. O trabalho foi realizado com duas crianças do Núcleo de Equoterapia do Caxangá Golf \& Country Club, suas respectivas famílias e profissionais que as acompanham. As técnicas utilizadas foram: observação das crianças nas sessões; entrevista com pais, terapeutas da instituição e outros cuidadores. Evidenciou-se a necessidade do vínculo da criança com o animal para seu envolvimento, bem como da família, no processo terapêutico. Constataram-se a necessidade da interação entre a criança, a equipe e outros praticantes no processo de socialização, e a adequação dos estímulos do ambiente equoterápico pela equipe interdisciplinar e pela família. Percebeu-se melhora da criança no aspecto socioafetivo, repercutindo nas relações familiares.
\end{abstract}

Palavras-chave: família; socioafetividade; equoterapia; criança prematura.

\begin{abstract}
This research was focused on studying children that have a neuropsychomotor development delay due to prematurity, and have being attended by an interdisciplinary therapy called therapeutic riding, a therapeutical approach that has the horse and its environment as primordial resources. The study was carried through two children from Caxangá Golf \& Country Club Nucleus of Equine therapy, their respective families and professionals, who accompany these children in the therapeutical process. The techniques used during the research were the children's sessions observation; interviews with parents and therapists from the institution and other "caretakers". According to this study, the straight vinculum between child and animal is very important for the children and their family's involvement to the therapeutic process. Also the child, the team and other practitioners interaction in the socialization process is important, as well as the stimulation adequacy of the equine therapy environment by the interdisciplinary team and the family. There have been a child's social-affective improvement aspect that reflects on the family relations.
\end{abstract}

Key words: family; socio-affectiveness; equine therapy; premature child.

A pesquisa teve como objetivo geral compreender as repercussões do tratamento equoterápico e seus elementos intervenientes no desenvolvimento socioafetivo da criança com atraso global por

$$
\boldsymbol{\nabla} \mathbf{\nabla} \boldsymbol{\nabla}
$$

1 Professora, Curso de Terapia Ocupacional, Universidade Federal de Pernambuco. Rua Prof. Moraes Rego, s/n. Cidade Universitária, 50750-901, Recife, PE, Brasil. Correspondência para/Correspondence to: J.F.QUEIROZ E-mail: <julifons@yahoo.com.br>.

2 Professora Doutora, Departamento de Psicologia, Universidade Católica de Pernambuco. Recife, PE, Brasil.

3 Membro do Laboratório de Interação Social e Familiar. Recife, PE, Brasil. 
prematuridade; e como objetivos específicos verificar a interação da criança com o cavalo e o grupo envolvido no ambiente equoterápico; compreender a intervenção dos profissionais da equoterapia como elemento facilitador desse processo; investigar as relações socioafetivas da criança na equoterapia por meio da percepção dos técnicos envolvidos no processo; analisar a percepção da família quanto à possível contribuição da equoterapia no desenvolvimento da criança; analisar as repercussões do processo equoterápico nas dificuldades interativas entre a família e a criança.

De acordo com a Teoria Sistêmica, base da terapia familiar desde a década de 50, o sistema familiar é um sistema aberto que se comunica com o meio exterior e por isso influencia o meio e por ele é influenciado (Bertalanffy, 1993). Os subsistemas influenciam um ao outro. O que acontece com um repercute no outro. Maldonado (1997) utiliza o termo "família grávida" ao enfatizar que o nascimento de um filho é uma experiência familiar. Então, tal gestação é compartilhada, não é solitária; a gravidez é uma experiência que pertence à família como um todo. E como um sistema, as partes são vistas no todo e o todo nas partes. Assim, a ênfase é dada ao grupo em detrimento do indivíduo.

Os sentimentos e significados relacionados à gestação e ao nascimento interferem na educação do novo membro da família. Segundo Tondo (1998), a família funciona como grupo intermediário entre sujeito e macrocontexto, no primeiro momento da vida.

Muitas são as exigências sociais quanto aos papéis familiares. Hoje ainda permanece o discurso de que o casamento na conotação de união estável, ideal e completo é aquele que gera um filho e o faz com perfeição, com cobranças bem maiores para a mulher. Segundo Maldonado (1997, p.16),"desde muitos séculos a fecundidade é tida como bênção divina, ao passo que a infertilidade é tida como castigo". Além disso, existe a responsabilidade social de procriar, perpetuar a espécie e dar continuidade à história familiar.

Quando pensamos em perpetuar nossa família, estão inclusos os desejos relacionados às possibilidades de crescimento do filho: capacidade de gerar, desenvolvimento intelectual, ascensão profissional, status social. Na gestação há um temor relacionado à "perfeição" do bebê. Segundo Brazelton (1994, p.19),"a contracepção e a escolha tornaram maior a responsabilidade para fazer com que o bebê seja perfeito em todos os aspectos." Percebe-se que nele a família concentra grandes expectativas.

Problemas durante a gestação e a antecipação do nascimento do bebê podem desencadear, nos pais, o sentimento de frustração. Maldonado (1997, p.26) traz uma citação de uma mãe que se encontrava em tal situação:"o neném estragou tudo, desmanchou o sonho do parto perfeito, da maternidade feliz". É uma situação de crise que precisa ser elaborada para que as relações afetivas, especialmente a relação mãe-bebê, não sejam comprometidas.

Outro ponto importante a ser discorrido é a respeito da separação entre a família e o bebê prematuro, de risco, uma vez que ele não vai para casa com sua família após seu nascimento, como planejado, ou melhor, idealizado. De acordo com Maldonado (1997), em casos de crianças que nascem com problemas graves ou com malformações, a separação após o parto torna-se particularmente penosa. Tal colocação pode ser ratificada pelo relato da mãe de uma criança com necessidades especiais, logo após o nascimento de sua filha:"eu me sentia repleta de amor e queria proteger e amparar minha filha, tê-la sempre no meu colo por achá-la tão indefesa"(Falkas, 1994, p.17).

De acordo com Vasconcellos (2003), pela perspectiva sistêmica, um comportamento adaptativo às variações do meio exibe uma auto-regulação importante para garantir a estabilização do sistema. A família pode apresentar vários mecanismos para garantir sua sobrevivência.

Faz-se necessário refletirmos a respeito da importância da relação afetiva com os pais e o bebê. Segundo Quintas (2000), na família o afeto indica o grau de harmonia ou de desarmonia que poderá compor a dinâmica daquele grupo; as interações funcionam, pois, como mola propulsora para o desenvolvimento dos seus membros. Bowlby (1998) acredita que as formas de comportamento de apego e os laços afetivos dele decorrentes se perpetuam por toda a vida, não se limitando à infância. Há, portanto, que se considerar, diante da importância das relações afetivas para o desenvolvimento, como elas se desenvolvem durante uma gestação marcada de incertezas no sistema familiar. 
Assim, é fundamental a preparação da família que, muitas vezes, acha que após o nascimento tudo estará tranqüilo, mas se depara com a frustração diante de uma criança com ritmo diferente e com marcantes diferenças dentro de uma visão social. Vale, portanto, um questionamento sobre a prematuridade e suas conseqüências para a criança e sua família.

\section{As conseqüências da prematuridade no desenvolvimento}

No Brasil, a cada ano, cerca de 11\% dos recém-nascidos chegam ao mundo prematuramente. Dentre eles, muitos morrem logo no início da vida, dependente de fatores como a idade gestacional e o baixo peso no nascimento (Bordin, Linhares \& Jorge, 2001). No caso da sobrevivência, há uma possibilidade de atraso no desenvolvimento. O índice elevado relacionado a doenças e à morte se deve, dentre diversos fatores, à imaturidade dos sistemas respiratório, circulatório e nervoso, dentre outros (Falcão, 1999; Martins Filho, 1996).

Segundo Hernandez (1996), os recém-nascidos pré-termo apresentam idade gestacional abaixo de 37 semanas. Dentro desse grupo, existe uma classificação relacionada à idade gestacional: a prematuridade extrema corresponde a uma gestação inferior a 30 semanas; a moderada, a uma gestação de 31 a 34 semanas e a limítrofe, a uma gestação de 35 a 36 semanas (Leone, Ramos \& Vaz, 2002).

Quanto às dificuldades que a criança prematura enfrenta, conforme Hernandez (1996), destacam-se a alta sensibilidade à informação sensorial e a incapacidade de evitar sua entrada, por falta de controle inibitório, causando inadequações na reação do bebê.

Sublinhando Barbosa, Lopes, Magalhães e Paixão (1999), há uma complexidade de fatores que podem influenciar o desenvolvimento infantil. Quanto maior o número de fatores de risco - dentre eles, grau de prematuridade (idade gestacional), baixo peso e intercorrências clínicas -, mais a criança está vulnerável a problemas no desenvolvimento. Outros fatores são o afastamento dos pais e a estimulação excessiva no período neonatal (Martins Filho, 1996). Percebe-se, assim, a importância do acompanhamento dos pais na fase de hospitalização do bebê recém-nascido pré-termo, principalmente por ser o ambiente hospitalar e, especialmente, de UTI inadequados para a evolução do bebê.

Conforme Brazelton (1994), o bebê prematuro tende a desenvolver-se num ritmo mais lento, devido à dificuldade de organizar um sistema nervoso tão frágil. É uma criança que, por ter dificuldades de lidar com os estímulos, pode não se envolver em brincadeiras, não interagir adequadamente e vir a apresentar dificuldades também no aprendizado (Pierce, 2000). Afora a possibilidade de atraso no desenvolvimento global da criança, os pais preocupam-se com fatores relacionados à sobrevivência do filho, especialmente nos primeiros meses de vida. Após essa fase, principalmente em casos de atrasos mais severos, a criança pode enfrentar estigma social por desenvolver-se "fora dos padrões", situação com a qual muitos pais têm dificuldade de lidar. Portanto, um nascimento prematuro acarreta uma série de complicações para o bebê e, extensivamente, para o contexto familiar.

De acordo com Rojas e Sternbach (1994), o discurso familiar contém os enunciados identificatórios que situam a criança no mundo. É nessa relação eu-outro introduzida pela família que irá se constituir a identidade, isto é, a partir do outro, da diferença. Portanto, a constituição da identidade está relacionada aos grupos de pertencimento.

É preciso criar oportunidades para que a criança com atraso por prematuridade amplie seu campo de relações interpessoais e passe a pertencer a outros grupos, além do familiar. Desde o nascimento da criança, é importante que a família seja orientada pela equipe de saúde quanto aos tratamentos necessários ao seu desenvolvimento global. As terapias objetivam favorecer o desenvolvimento de aquisições e devem ser indicadas de acordo com as carências e possibilidades da criança, ou seja, devem ocorrer num ritmo apropriado.

Magalhães et al. (1999) esclarecem que o programa de acompanhamento dessas crianças deve prosseguir após os dois anos de idade, já que os distúrbios da prematuridade se fazem sentir, também, para além dessa faixa etária.

\section{A equoterapia e o processo de socialização}

A equoterapia é um método terapêutico e educacional que utiliza o cavalo dentro de uma 
abordagem interdisciplinar, nas áreas de saúde, educação e equitação, buscando o desenvolvimento biopsicossocial de pessoas portadoras de deficiência e/ou de necessidades especiais (Ande, 1999).

De acordo com Dias e Medeiros (2002), o cavalo possui três andaduras naturais: passo, trote e galope. Dentre essas, a mais utilizada na equoterapia é o passo, sua andadura natural que se caracteriza por ser ritmada, cadenciada e em quatro tempos, ou seja, ouvem-se quatro batidas distintas, nítidas e compassadas que correspondem ao pousar do animal. É a andadura mais freqüente por conta da riqueza dos movimentos tridimensionais (Dias \& Medeiros, 2002).

Para Spink (1993), o movimento causado pelo passo se assemelha ao da marcha humana, pois o dorso do cavalo realiza um movimento tridimensional: para frente e para trás; para um lado e para outro; para cima e para baixo. Isso requer do praticante reações de equilíbrio e de retificação postural para que possa se manter sobre ele. Esse movimento é transmitido ao cérebro do praticante pelas inúmeras terminações nervosas aferentes. O cérebro, por sua vez, manda informações ao corpo para que novos ajustes motores sejam realizados por meio do comportamento adaptativo, que é resultante também dos estímulos sensoriais da equoterapia.

São inúmeros os estímulos relacionados ao cavalo. Seu ambiente é natural, diferenciado da área urbana, constituído por picadeiro (piso em terra) e área exterior onde podem ser encontrados outros animais, plantas, árvores, baias, etc. Há uma riqueza de informações proprioceptivas e cinestésicas, sensações de posição do corpo e de movimento durante o contato físico entre o praticante (como é chamado o paciente da equoterapia) e o animal (Lallery, 1992). Essas informações propiciam uma nova imagem do corpo do praticante e, quando associadas à abordagem dos terapeutas, segundo Lallery (1992), favorecem o desenvolvimento do eu.

Conforme Spink (1993), o animal atua não apenas como um espelho, onde são projetadas as dificuldades, progressos e vitórias, mas também como um novo estímulo que propicia novas percepções e vivências, atribuição de novos significados. Por meio da relação com o cavalo, a criança pode aprender a controlar suas emoções iniciais, como o medo, enfrentando o desafio de montá-lo e, sentada numa posição superior, direcioná-lo. Cavalgar um animal dócil, porém de porte avantajado, leva o praticante a experimentar sentimentos de liberdade, independência e capacidade: sentimentos esses importantes para a aquisição da autoconfiança, realização e auto-estima.

\section{Método}

O Núcleo de Equoterapia do Caxangá Golf \& Country Club, local onde foi realizada a pesquisa, é formado por uma equipe interdisciplinar composta por profissionais especialistas no trato com o animal: veterinário, tratador, auxiliar-guia (responsável pela condução do animal durante as sessões) e o equitador (profissional que detém conhecimento sobre o animal e acompanha os praticantes em conjunto com a equipe durante as sessões). Os terapeutas são das seguintes áreas: Fisioterapia, Psicologia, Terapia Ocupacional, Fonoaudiologia e Psicopedagogia. Em geral, dois profissionais acompanham lateralmente o praticante durante a sessão, mas, se necessário, um dos terapeutas monta com ele.

Na chegada do praticante, a equipe solicita laudo médico, exames relacionados ao diagnóstico ou possível diagnóstico e autorização médica para constatação da ausência de contra-indicações à equoterapia. É realizada anamnese com os responsáveis pela criança e uma avaliação física para, em seguida, serem discutidas, em reunião de equipe, as indicações do cavalo e dos profissionais para acompanhar a criança de acordo com suas necessidades. Há, periodicamente, reavaliações, e, sendo necessária alguma mudança, ela é trabalhada com a criança antecipadamente. As reuniões de equipe são realizadas para estudo de casos, discussões científicas e administrativas. A equipe também troca informações com as famílias para a compreensão do contexto do dia-a-dia do praticante, bem como para orientações relacionadas aos cuidados da família com a criança.

Os participantes da pesquisa foram duas crianças com atraso de desenvolvimento por prematuridade - em variadas aquisições (sensório-motoras, cognitivas, emocionais e sociais) - que estavam em processo terapêutico no núcleo há mais de um ano, com idades, na época, entre três e quatro anos e que são apresen- 
tadas no texto com nomes fictícios, assim como os outros participantes. Participaram do processo seus familiares (dois para cada criança) e/ou outros responsáveis (uma babá, no caso de Larissa) e profissionais da instituição (três para cada criança) envolvidos no atendimento.

A idéia inicial era fazer a relação entre a equoterapia e a prematuridade. Os sujeitos foram escolhidos por apresentarem faixa etária e período de início na equoterapia aproximados. Outro fator foi a semelhança entre elas quanto às reações aos estímulos durante as sessões, dado observado numa pesquisapiloto. Essa defensividade é relatada por Hernandez (1996), que destaca, nesses casos, a alta sensibilidade à informação sensorial, caracterizada pela aversão a alguns estímulos do ambiente, tais como sons, brilho, iluminação, texturas e toque (contato corporal).

Tal aversão dificulta a exploração do ambiente pela criança, tornando-a pobre, bem como a relação com as pessoas, o que dificulta o desenvolvimento socioafetivo e impede o surgimento de demais aquisições. Além disso, esse processo é intersectado pela vivência familiar que, na situação de prematuridade extrema, sofre ameaça de comprometimento da afetividade. Por essas características foram priorizados os aspectos socioafetivos na pesquisa.

Os dados necessários para a pesquisa foram coletados por meio de: 1) observação sistemática da criança durante seu atendimento na equoterapia durante um período de seis meses (duração, em média, da pesquisa de campo) e dos responsáveis enquanto acompanham a criança; 2) entrevistas semi-estruturadas com os familiares, a babá de uma das crianças e os profissionais que acompanham o seu desenvolvimento na equoterapia. O material foi registrado por meio de gravação e, posteriormente, transcrito. Foi utilizado um roteiro com perguntas disparadoras para a coleta de informações. Após os procedimentos referidos, os dados colhidos foram analisados, discutidos e relacionados à literatura consultada.

Para atender aos objetivos da pesquisa, foi realizada análise qualitativa dos dados obtidos nas entrevistas, observações e sistematização de tais informações.
Pela compreensão de Bogdan e Biklen (1994, p.49) a respeito da pesquisa qualitativa,

Ao recolher dados descritivos, os investigadores qualitativos abordam o mundo de forma minuciosa ... . A abordagem da investigação qualitativa exige que o mundo seja examinado com a idéia de que nada é trivial, que tudo tem potencial para constituir uma pista que nos permita estabelecer uma compreensão mais esclarecedora do nosso objeto de estudo.

Segundo esses autores, a observação participante e a entrevista em profundidade são as estratégias mais representativas da investigação qualitativa. $O$ registro das observações dos sujeitos na equoterapia foi realizado por meio de notas de campo, compreendidas como: "relato escrito daquilo que o investigador ouve, vê, experiencia e pensa no decurso da recolha ..." (Bogdan \& Biklen, 1994, p.150). As observações seguiram um roteiro que continha os aspectos mais importantes a serem analisados, de acordo com os objetivos da pesquisa, seguindo uma ordem de início, meio e fim das sessões: afastamento da criança dos responsáveis e sua aproximação dos terapeutas e do cavalo (vivências de apego e desapego); reação aos movimentos do animal e estímulos oferecidos; comunicação com o animal, terapeutas e outras pessoas do ambiente (colegas da equoterapia e suas famílias); comportamento lúdico; despedida do cavalo e dos terapeutas e retorno à família; comportamento dos responsáveis durante a sessão, na espera de suas crianças.

\section{Procedimentos}

No caso de Alice, as entrevistadas foram a avó materna e a mãe adotiva (tia materna), pois, devido ao falecimento da mãe biológica no processo da gravidez, elas são as principais responsáveis pela criança. No caso de Larissa, foram seus pais biológicos. Nesse segundo caso, houve também a realização da entrevista com a babá, com quem a criança tem um vínculo significativo por permanecer grande parte do tempo em sua companhia. Seus cuidados interferem no desenvolvimento de Larissa e, por isso, ela foi elemento essencial na coleta e análise de dados. Serão apresentados sucintamente alguns dos dados analisados, selecionados por serem uns dos mais significativos, de acordo com os objetivos da pesquisa (Tabelas 1 e 2). 
Tabela 1. Casos clínicos

\begin{tabular}{|c|c|c|c|}
\hline \multirow{2}{*}{ Casos clínicos } & & \multicolumn{2}{|c|}{ Crianças } \\
\hline & & Alice & Larissa \\
\hline \multirow{6}{*}{ Dados } & Peso ao nascer & $905 \mathrm{~g}$ & $595 \mathrm{~g}$ \\
\hline & Idade gestacional / Classificação da prematuridade & 26 semanas / extrema & 25 semanas / extrema \\
\hline & Período de hospitalização & Cerca de 4 meses & Cerca de 4 meses \\
\hline & Causa da prematuridade & Adoecimento da mãe & Problemas do útero materno \\
\hline & Idade (período da pesquisa) & 4 anos & 3 anos e meio \\
\hline & Idade (entrada na equoterapia) & 1 ano e 9 meses & 1 ano e 9 meses \\
\hline
\end{tabular}

Tabela 2. Acompanhamento terapêutico na equoterapia.

\begin{tabular}{lll}
\hline & Caso Alice & Caso Larissa \\
\hline Profissionais entrevistados & Fonoaudióloga, psicóloga e psicopedagoga & Fisioterapeuta, psicóloga e terapeuta ocupacional \\
Atividades desenvolvidas & Estórias;faz-de-conta simples;fatos do dia-a-dia; & Interação e cuidados com o animal; jogo de bola \\
(durante a montaria) & visita à casa do cavalo (baia); cantos, danças, o & com ocolega da sessão; faz-de-conta simples; cantos; \\
& bater palmas; jogo de bola & exercícios para melhora da coordenação motora \\
& & ampla e fina por meio do lúdico \\
\hline
\end{tabular}

\section{Resultados}

Os resultados apresentados, colhidos dos responsáveis, foram confirmados pelo comportamento familiar durante as observações das sessões, bem como pelos relatos da equipe.

Quanto às relações familiares, no caso de Alice, após a morte de sua mãe biológica (Bruna), primogênita da família, há uma mudança de papéis, de forma que sua tia materna, solteira, que ocupava o segundo lugar de nascimento, assume o lugar de primogênita, bem como a maternidade da criança, embora sua avó materna tenha almejado cuidar da criança. Há uma reorganização familiar após a perda de um membro que, segundo os relatos, desempenhava um papel de : destaque no favorecimento da unidade familiar. Observou-se que Alice parece ser uma extensão de Bruna para os membros da família e, após o enterro de sua mãe, quando a criança ainda estava na Unidade de Terapia Intensiva (UTI), ela passou a ser o centro das atenções. O pai biológico que namorava Bruna durante a gestação se ausentou após sua morte e, atualmente, não tem vínculo com a criança. No caso de Larissa, o pai é bastante presente, observando-se cumplicidade do casal desde a gestação.
Nos dois casos foram detectados os seguintes aspectos nas relações: reorganização familiar pela prematuridade; intensificação dos laços, que pode ocorrer no sistema familiar impactado por um evento estressor; tomada de decisões conjunta; mobilização da família para o estímulo ao desenvolvimento da criança, bem como atribuição de importância ao afeto, verbalizado como um propulsor para esse processo de evolução, tal qual a citação de Quintas (2000). As visitas familiares durante a hospitalização das crianças, bastante constantes segundo relatos, foram fundamentais para a minimização dos efeitos da prematuridade sobre o desenvolvimento, como referenciado por Martins Filho (1996).

Os sentimentos relatados pelas famílias relacionados à prematuridade são bastante semelhantes nos dois casos: fazem referência à dor pela situação de separação das filhas pela hospitalização, tal qual citado pelo pai de Larissa: "A gente não tinha nem acesso a ela", relembrando Maldonado (1997), quando descreve tal separação como penosa.

Surgem nesse período sentimentos ambivalentes quanto ao investimento afetivo: se preparar para a morte da criança ou crer em sua sobrevivência? A avó de Alice refere dúvida quanto à preparação do enxoval; 
nas duas entrevistas percebe-se a brincadeira da família com os fatos ocorridos como meio de amenizar recordações de momentos de estresse; relato da ansiedade para levar as filhas para casa, bem como as incertezas quanto aos cuidados dirigidos a seres tão frágeis; as crenças relacionadas às religiões das famílias são citadas e percebidas como bases fundamentais no enfrentamento das dificuldades; os pais de Larissa fazem comparações com outras crianças, demonstrando por meio desse comportamento dificuldade com as diferenças. Também o fazem a tia e a avó de Alice, porém mais significativamente no início do desenvolvimento da criança.

Quanto ao desenvolvimento dos sujeitos da pesquisa, as queixas familiares cruzam com os aspectos mais trabalhados pelos profissionais da equoterapia. A área da linguagem é alvo de maior ansiedade para a família de Alice, assim como a aquisição da marcha, no caso dos pais de Larissa. Seu atraso motor, de fato, é mais significativo do que o de Alice, que já consegue andar. A superproteção pode interferir negativamente no surgimento das aquisições, pois, muitas vezes, o julgamento da criança como frágil impede sua exploração do mundo rumo à independência, sentimento traduzido por Falkas (1994) quando descreve seu bebê como indefeso. $\mathrm{O}$ assunto surgiu espontaneamente nas entrevistas. A mãe adotiva de Alice refere evitar tal comportamento; os pais de Larissa também se posicionam dessa forma, porém sua babá sente dificuldades e verbaliza que, apesar de tentar, não consegue deixar de superproteger a criança.

De modo semelhante, as famílias expressam a importância do feedback da evolução da criança para a continuidade de seus investimentos. Valorizam a participação e a unidade familiar, assim como a realização das terapias necessárias, porém evitam sobrecarga e excesso de estímulos. Reclamam da dificuldade em conciliar as atenções para com a criança e a responsabilidade com o trabalho.

A respeito da evolução dessas crianças por meio da equoterapia, percebemos que ela funciona como um feedback positivo para a família em relação ao seu investimento. Esse, representado pelas atitudes familiares, funciona como output do sistema e o desenvolvimento da criança funciona como input. Esse "balanço" mostra à família que as mudanças ocorridas no sistema familiar, diante das às conseqüências da prematuridade, "valeram a pena". Foram mudanças qualitativas em seu funcionamento. A relação entre inputs e outputs promove a auto-regulação. Por meio das informações sobre a conduta familiar passada, o sistema se torna capaz de ajustar sua conduta futura. Bertalanffy (1993) e Vasconcellos (2003) descrevem bem esses conceitos.

Ainda fazendo referência a Vasconcellos (2003), a retroalimentação ou feedback é negativo quando a família tenta minimizar os desvios do sistema, ou seja, quando percebe que está conduzindo erroneamente. Isso é comum quando a família tenta "acertar" quanto à educação das crianças. Por exemplo, quando é introduzido o assunto sobre regras e limites, a babá de Larissa diz perceber que precisa modificar sua conduta de superproteção à criança por Ihe ser prejudicial, algo já referido pelos pais.

Ainda sobre a equoterapia, no caso de Alice predomina a presença da mãe adotiva nas sessões. Já no caso de Larissa, a presença do pai. Quanto às expectativas, a mãe adotiva e a avó de Alice referem à sua entrada na equoterapia como "um marco". Os pais de Larissa referem evolução, mas aquém das expectativas. Isso parece se explicar por dois motivos, dentre outros: 1) Larissa tem um comprometimento global maior; 2) as dificuldades de seus responsáveis no enfrentamento das diferenças são maiores, de acordo com a entrevista e o relato da equipe de equoterapia. Todos reconhecem a equoterapia como um espaço voltado à evolução da criança; procuram, segundo a mãe adotiva de Alice,"tudo o que pudesse, ou melhor, possa somar...". A credibilidade na abordagem terapêutica e no trabalho da equipe parece ser fundamental para que o processo equoterápico seja adequado. A própria equipe cita que esse investimento familiar é fundamental. Pelos dados colhidos com os responsáveis, pôde-se perceber que a equoterapia funciona como um espaço de vivência do apego e desapego, pois há o momento de afastar-se e o de reaproximar-se da família, bem como permite a formação de novos vínculos, favorecendo o desenvolvimento da identidade. Segundo a equipe e os cuidadores, a adaptação ao processo terapêutico dependente da relação entre criança, cavalo, equipe e ludicidade. 


\section{Considerações Finais}

Por meio da realização deste trabalho, pudemos perceber as dificuldades que a família enfrenta diante da prematuridade e da necessidade de lidar com a possibilidade de morte e atraso no desenvolvimento, marcando diferenças em relação ao padrão "normal"e, assim, social. Observou-se que o sistema familiar precisou reorganizar-se em conseqüência do problema existente.

Retomando os conceitos de Vasconcellos (2003), compreende-se o fato de que as famílias em estudo utilizaram diversos meios de auto-regulação para a estabilização do sistema, tais como: 1) a inclusão de toda a família no processo terapêutico das crianças; 2) a crença religiosa como alicerce; 3) a intensificação dos laços afetivos entre os membros; 4) o suporte de profissionais diversos para orientar como proceder; 5 ) as expectativas quanto ao desenvolvimento das crianças; 6) a própria evolução das crianças.

Por meio das observações de algumas sessões das crianças - Alice e Larissa -, bem como das entrevistas, percebeu-se a sua evolução quanto à interação com o cavalo e o grupo envolvido no ambiente equoterápico. Inicialmente demonstravam angústia no contato com o animal e com os estímulos decorrentes de sua marcha. Atualmente elas sentem prazer em estar nesse espaço e anseiam pelo momento da terapia. Segundo relatos dos responsáveis, as crianças falam sobre os cavalos em casa, sentem saudade e, ao chegarem na equoterapia, expressam alegria ao vê-los. São comportamentos que nos fazem acreditar que exista um laço afetivo entre a criança e o animal construído no decorrer do tratamento.

As características relacionadas à socioafetividade e arroladas pela equipe que acompanha Larissa foram as mesmas referenciadas pelo grupo que acompanha Alice: equoterapia como espaço de exploração e descoberta; ambiente rico de possibilidades, evocando o desenvolvimento de potencialidades, com um diferencial pela relação de domínio sobre o animal; relação com pessoas nas sessões; presença de regras sociais na equoterapia que favorece o desenvolvimento do comportamento da criança no meio social; relação com o cavalo; aceitação incondicional; jogo de limite e continuidade entre o corpo da criança e o do cavalo.
Enquanto encerra seu corpo e inicia o do cavalo, a criança tem a sensação de que a marcha do cavalo, que tem semelhança com a marcha humana, é também a sua marcha. Há uma sintonia nessa ritmação. Esse momento faz-nos lembrar da sensação simbiótica mãe-bebê durante a gestação e nascimento.

Segundo relato da psicóloga entrevistada, a equoterapia surge como uma oportunidade de reviver os traumas de UTI, dadas algumas semelhanças: separação física da mãe e oferta de estímulos. Apesar das possíveis semelhanças, a criança encontra-se num outro momento de vida, mais amadurecida e mais preparada para lidar com o novo contexto. Além disso, como espaço terapêutico, a equoterapia é realizada por uma equipe cujo objetivo é organizar as informações que chegam à criança. É, portanto, oferecida ao praticante a oportunidade de reelaborar os traumas da UTI e ressignificar os estímulos do ambiente. As crianças em foco têm desenvolvido a capacidade de aceitar ou negar informações que lhe são oferecidas, ou seja, de realizar escolhas, o que é bastante significativo.

Observamos que as duas famílias conseguem perceber que a equoterapia favoreceu o desenvolvimento das crianças, porém suas expectativas interferem nesse olhar. Foi comum nos relatos dos responsáveis o comentário sobre o prazer, a motivação das crianças pela freqüência à equoterapia, o que facilita esse processo, bem como o aprendizado relacionado ao afastamento entre criança e família no momento da sessão.

Observando-se as fases relacionadas ao comportamento de apego e desapego, pois inicialmente as crianças ofereciam resistência para se afastarem da família, verifica-se que, por meio do vínculo afetivo com o cavalo, foi "superada" a distância da família, embora ainda fosse necessário vê-la constantemente. Atualmente conseguem afastar-se sem angústia. Aspecto que é favorecido pela família e pela equipe que trabalhou as relações de lealdade e confiança necessárias para um distanciamento sossegado.

Portanto, a equoterapia funciona também como espaço social que permite idas e vindas, instalando, por vezes, "angústia" para a criança e sua família, sentimento esse que, no contexto, é fundamental para o amadurecimento emocional da criança. Lembrando Vasconcellos (2003), os graus de "permeabilidade" das 
fronteiras do sistema aberto o tornam mais ou menos susceptível às influências de seu ambiente. As trocas permitidas pelas famílias participantes da pesquisa favoreceram, portanto, o desenvolvimento de Alice e Larissa, bem como o crescimento de cada família como um todo.

Por meio da melhora na socioafetividade, essas famílias podem se fazer compreender e serem compreendidas pelas crianças. A criança já não é mais percebida como um ser frágil e indefeso, pois está a caminho da independência do círculo familiar, em direção à ampliação do círculo social, o que representa seu crescimento como sujeito.

Um dos pontos mais significativos da pesquisa relaciona-se com a possibilidade de conhecermos as singularidades dos casos clínicos. A equoterapia poderia beneficiar seus praticantes de diferentes formas, tal como encontramos na revisão teórica, porém, nunca saberíamos quão profundas podem ser essas mudanças para a criança e para o contexto familiar, se antes não conhecêssemos um pouco de sua história. Também não poderíamos compreender a relação entre essas famílias e a equoterapia. Isso faz com que o estudo qualitativo seja diferenciado na medida em que podemos aprofundar nossos conhecimentos acerca dos fatos experienciados. A equoterapia beneficia cada praticante de forma singular, de acordo com sua história, que é única.

\section{Referências}

Associação Nacional de Equoterapia. (1999). Fundamentos básicos sobre equoterapia. In Coletânea de trabalhos do I Congresso Brasileiro de Equoterapia. Brasília: Associação Nacional de Equoterapia.

Bertalanffy, L. V. (1993). Teoria general de los sistemas: fundamentos, desarrollo, aplicaciones. Madrid: Fondo de Cultura Económica.

Bogdan, R. C., \& Biklen, S. K. (1994). Investigação qualitativa emeducação:uma introdução a teoria e aos métodos. Porto: Porto Editora.

Bordin, M. B. M., Linhares, M. B. M., \& Jorge, S. M. (2001). Aspectos cognitivos e comportamentais na média meninice de crianças nascidas pré-termo e com muito baixo peso. Psicologia: Teoria e Pesquisa, 17 (1), 49-57.

Bowlby, J. (1998). Perda: tristeza e depressão (Vol. 3, 2. ed.). São Paulo: Martins Fontes, 1998.
Brazelton, T. (1994). Momentos decisivos do desenvolvimento infantil. São Paulo: Martins Fontes.

Dias, E., \& Medeiros, M. (2002). Equoterapia: bases e fundamentos. Rio de Janeiro: Revinter.

Falcão, M. ( 1999). Seguimento do recém-nascido de risco. In J. Fazio et al. (Coords.), Cuidados intensivos no período neonatal (Seção 15, pp.333-338). São Paulo: Sarvier.

Falkas, Y. M. (1994). Portas entreabertas: crescendo com os limites de minha filha. São Paulo: Plexus.

Hernandez, A. M. (1996). Atuação fonoaudiológica em neonatologia: uma proposta de intervenção. In C. R. F. Andrade. Fonoaudiologia em berçário normal e de risco (Vol.1, cap.3, pp.43-97). São Paulo: Lovise.

Lallery, H. (1992). A equitação terapêutica. Brasília: Associação Nacional de Equoterapia.

Leone, C. R., Ramos, J. L. A., \& Vaz, F. A. C. O. (2002). Recémnascido pré-termo. In E. Marcondes, et al. Pediatria básica: pediatria geral e neonatal (9a ed., cap.8, pp.348-352). São Paulo: Sarvier.

Magalhães, L. C., Barbosa, V. M., Lopes, K. C. \& Paixão, M. L. (1999). Estudo longitudinal do desenvolvimento de recém-nascidos pré-termo: avaliação na idade pré-escolar. Revista Brasileira de Neurologia, 35 (4), 87-93.

Maldonado, M. T. (1997). Psicologia da gravidez: parto e puerpério (14a ed.). São Paulo: Saraiva.

Martins Filho, J. (1996). Prematuridade. In F. Fiqueira, O. Ferreira \& J. Alves. Pediatria: Instituto Materno Infantil de Pernambuco (2a ed., cap.5, pp.139-144). Rio de Janeiro: Medsi.

Pierce, D. O. ( 2000). Potencial da recreação com objetos para lactentes e crianças na primeira infância em risco de atraso no desenvolvimento. In L. D. Parham \& L. S. Fazio. A Recreação na terapia ocupacional pediátrica (cap.6, pp.86-111). São Paulo: Santos.

Quintas, F. (2000). A mulher e a família no final do século XX. Recife: FJN, Editora Massangana.

Rojas, M. C., \& Sternbach, S. (1994). Entre dos siglos: una lectura psicoanalítica de la posmodernidad. Buenos Aires: Lugar Editorial.

Spink, J. (1993). Developmental riding therapy: a team approach to assessment and treatment. Texas: Therapy Skill Builders.

Tondo, C. T. (1998). Teoria sistêmica. In Y. S. Souza \& M. L. T. Nunes (Orgs.), Família, organização e aprendizagem: ensaios temáticos em psicologia. Porto Alegre: PUCRS.

Vasconcellos, M. J. E. (2003). Pensamento sistêmico: o novo paradigma da ciência (2. ed.). Campinas: Papirus.

Recebido em: 9/9/2005

Versão final reapresentada em: 31/3/2006

Aprovada em: 9/5/2006 
